Didáctica Geográfica n 19, 2018,pp. 169-196

ISSN: 0210-492-X

D.L: M-3736-2014

\title{
LOS PAISAJES RURALES EN LOS PROYECTOS EDUCATI- VOS DE ENSEÑANZA PRIMARIA. UNA PROPUESTA PARA LA COMARCA DE TIERRA DE CAMPOS
}

Erica Morales Prieto ${ }^{1}$ Enrique Delgado Huertos ${ }^{2}$

Recibido: 12/09/2017

Aceptado: 15/09/2018

\section{RESUMEN:}

La literatura científica sobre los paisajes rurales cuenta con una dilatada trayectoria y es extraordinariamente abundante. No sucede lo mismo con el tratamiento educativo de estos paisajes, sobre los cuales apenas se han elaborado recursos didácticos. Presentamos aquí un proyecto educativo para el ciclo superior de la enseñanza Primaria en el que, a través de una salida de campo a la Tierra de Campos de Palencia y Valladolid, se presentan un abanico de propuestas y actividades para realizar antes, durante y una vez realizado el viaje, así como información de interés y recomendaciones para el profesorado que desee ponerlo en práctica.

\section{Palabras Clave:}

Paisaje rural, Educación Primaria, Tierra de Campos, Torremormojón, Villalón de Campos.

1 Universidad de Salamanca. emoralesprieto@usal.es. Dpto. Geografía E.U. de Magisterio de ZamoraAvda. Cardenal Cisneros, 34. 49029 Zamora

2 Universidad de Valladolid. joseenrique.delgado@uva.es. Departamento de Geografía. Facultad de Educación. Campus de la Yutera. Avenida de Madrid, 50. 34004 PALENCIA 


\section{Abstract:}

The scientific literature on rural landscapes has a vast trajectory and is extraordinarily abundant. This is not so with the educational treatment of these landscapes, on which educational resources have hardly been developed. Here we present an educational project for the upper cycle of primary education in which, through a field trip to Tierra de Campos, Palencia and Valladolid, a range of proposals and activities are suggested before, during and after the trip, as well as relevant information and recommendations for teachers who want to put it into practice.

\section{KEYWORDS:}

Rural landscape, Primary education, Tierra de Campos, Torremormojon, Villalon de Campos.

\section{RÉSUMÉ:}

Depuis bien longtemps, il existe une extraordinaire et abondante littérature scientifique sur les paysages ruraux. Mais, il n'arrive pas la même chose avec le traitement éducatif de ces paysages, sur lesquels on n'a presque élaboré d'outils ou de matèriels didactiques. Ici, on propose un projet éducatif pour les derniers cours de 1'Enseignement Primaire où, à travers une sortie à la campagne de «Tierra de Campos de Palencia y Valladolid», on offre un éventail d'initiatives et d'activités pour réaliser avant, pendant et une fois effectué le voyage, ainsi que des informations d'intérêt et des recommandations pour les professeurs qui veulent le mettre en pratique.

\section{Mots-CLéS:}

Paysages ruraux, Éducation primaire, Tierra de Campos; Torremormojón, Villalón de Campos.

\section{INTRODUCCIÓN: LA IMPORTANCIA OTORGADA A LOS PAISAJES RURALES POR LA GEOGRAFÍA ESPAÑOLA}

Hablar de paisaje supone hablar de todos los elementos que conforman el medio en el que nos encontramos. Entre las numerosas definiciones existentes se puede tomar como referencia la que se realiza en el Convenio Europeo del Paisaje (2000, p. 2) "por paisaje se entenderá cualquier parte del territorio tal como la percibe la población, cuyo carácter sea el resultado de la acción y la interacción de factores naturales y/o humanos", y que se identifica como "un elemento importante de la calidad de vida de las poblaciones...en los medios urbanos y rurales, en las zonas degradadas y de gran calidad, en los espacios 
de reconocida belleza excepcional y en los más cotidianos", Monkhouse distingue, en este sentido, hasta seis tipos de "paisaje": paisaje cultural, paisaje físico, paisaje humano, paisaje natural, paisaje relicto y paisaje urbano (Tort, 2004, p. 137). Para autores como Delgado y Ojeda (2009, p. 94) "el paisaje puede entenderse como el resultado de un proceso en el que un conjunto de componentes naturales, que conforman el armazón físico de un ambiente o espacio geográfico, se convierte en territorio o país a través de una secular historia de conquista, apropiación, organización y normalización por parte de una comunidad humana y termina siendo codificado o metamorfoseado en paisaje por unas percepciones, representaciones y simbolizaciones culturales"

Los paisajes rurales, como afirma Plaza Gutierrez (2016), han constituido una referencia central de la Geografía desde las aportaciones que hiciera la Geografía francesa, en la década de 1950, hasta la recopilación en la década de 1980 por la Asociación de Geógrafos Españoles con la obra colectiva "Los paisajes rurales de España”, una referencia que muestra la importancia de este campo temático. A ese estudio le han sucedido otros igualmente fundamentales para el conocimiento de los paisajes rurales, tal es la obra homenaje al profesor Ángel Cabo Alonso, titulada "El medio rural español. Cultura, Paisaje y Naturaleza" editada en 1992. También el imprescindible trabajo, coordinado por los profesores Molinero, Ojeda y Tort "Los paisajes agrarios de España: caracterización, evolución tipificación", editado por el MARM en 2012 y la imprescindible obra, estructurada en dos tomos, "Atlas de los paisajes agrarios de España" editada por el Ministerio de Agricultura, Alimentación y Medio Ambiente en 2013. Por citar una última obra colectiva, el XVII Coloquio de Geografía Rural (Colorural 2014) en el apartado dedicado a Desarrollo rural: sostenibilidad social, económica y ambiental, patrimonio y capital territorial, recoge nueve comunicaciones referidas al paisaje rural desde esta perspectiva.

No cabe duda de que el paisaje ha sido, aunque no exclusivamente, objeto propio y preferente de la Geografía. Una disciplina donde las relaciones hombre-medio se presentan como un sistema abierto y dinámico donde se interrelacionan todos los elementos que los conforman, bióticos, abióticos y antrópicos. Bajo este paradigma la geografía aparece, epistemológica y metodológicamente como una disciplina relevante para el estudio del paisaje con un importante potencial pedagógico cuyo estudio se basa en la comprensión de las relaciones entre los elementos que lo conforman y la dimensión espacio-temporal de los diversos modelos de organización que resultan de la interacción entre los seres humanos y su entorno (Pena Vila, 1997, p. 68), y que en el presente trabajo se focaliza en los paisajes rurales.

El tratamiento o estudio del paisaje permite adecuar el tratamiento didáctico que se le quiera otorgar al nivel con el que deseamos trabajar, al mismo tiempo, que va a permitir a los alumnos adquirir un desarrollo progresivo de sus capacidades cognitivas, 
contribuye a la adquisición de competencias específicas y, al mismo tiempo les aporta una riqueza conceptual, procedimental, y multidisciplinar ya que se puede trabajar desde diferentes materias.

Por su parte, tal y como define Molinero (2011, p.5) el paisaje agrario actual, que es parte del paisaje rural "no se entiende sin una mirada al pasado. Es un legado de los grupos humanos que a lo largo de la historia han ocupado un territorio, lo han explotado y lo han organizado; y en cada momento histórico lo han hecho según sus capacidades, intereses y cultura, pero siempre aprovechando las condiciones del medio ecológico. Con el paso del tiempo se ha producido una homogeneización paisajística, por uniformización técnica, que, sin embargo, no ha impedido el mantenimiento de paisajes distintos y dispares...", por eso mismo, el paisaje rural es el resultado de la interacción entre la sociedad y el medio en que se asienta (Hernández, 2009, p. 170, en Plaza Gutiérrez, 2016) y cuenta con unos rasgos propios que se remontan a un modelo histórico o tradicional, con unos rasgos que se remontan al pasado, con un origen medieval, o incluso, premedieval. Un paisaje sometido, como cualquier otro, a constantes cambios cuyo grueso se produjo en la segunda mitad del siglo XIX vinculado al proceso de modernización del país (Fernández García, 2010, p. 142-143). Consecuentemente, los cambios aún tienen sus secuelas en la actualidad, muchos de estos espacios fueron abandonados, siendo la tónica general de los espacios rurales a nivel nacional, mientras que han sido pocos los municipios rurales que han crecido o se han modernizado, exceptuando los más próximos a las ciudades que se han adaptado al proceso de periurbanización, como consecuencia de la demanda de vivienda más barata, frente a los municipios que se vieron afectados por la modernización agraria y, consecuentemente, por el abandono y que aún hoy, mantienen inalterada la imagen del rural profundo, en la que la actividad agraria predomina sobre otra cualquiera.

La imagen de atonía y abandono que caracteriza a los espacios rurales, y más si hablamos del caso particular de Castilla y León, y del caso que nos ocupa, la comarca de Tierra de Campos, sus paisajes, se diferencian de los espacios urbanos no solo por la propia morfología y estructura de poblamiento, sino también por ciertos elementos identificativos como determinadas construcciones de uso agrario, cierto caserío, infraestructuras agrarias, delimitaciones parcelarias.... elementos que van a ser la clave para nuestro trabajo ya que el ejercicio de estudiar el paisaje rural va a permitir a los alumnos de primaria adquirir conocimientos, técnicas y herramientas aplicadas a un paisaje concreto que posteriormente podrá extrapolar a otros, de manera que el alumno descubrirá una "imagen del conjunto ya que los elementos que identifica no son piezas aisladas, sin referencia a un contexto ni relación mutua, su explicación se realiza dentro de un marco coherente de la imagen que tenemos del territorio que es lo que llamamos paisaje" (Sancho Comins, 2016). Pero también, el acercamiento al paisaje rural les 
posibilitará a los escolares el desarrollo de valores tales como el aprecio del patrimonio cultural, la necesidad de proteger el patrimonio natural y la biodiversidad, el interés de la vida rural, la aportación de la agricultura sostenible al medio ambiente y la lucha contra la despoblación.

\section{LOS PAISAJES EN EL CURRÍCULUM DE EDUACIÓN PRIMARIA Y SU INTERÉS PEDAGÓGICO}

\subsection{Los paisajes en el currículum}

No es una novedad hablar de la importancia de los paisajes en el currículum ya que han sido muchos los autores que han hecho una reflexión al respecto, véase el caso de Pérez Urraza et al. (2015) en cuyo trabajo se hace una recapitulación del tratamiento del paisaje como concepto curricular en las sucesivas leyes educativas durante los siglos XX y XXI.

Para Delgado y Ojeda (2007, p. 11) “en la primaria debe potenciarse la contemplación global del paisaje desde aspectos vivenciales y mediante la estimulación de destrezas como la observación, descripción, comparación y clasificación"

Sancho Comins (2016, p. 419) señala que "no importa si la mirada es superficial, el objetivo es que perciban los elementos visuales significativos e incluso puede derivar una primera apreciación de la estructura morfológica del paisaje" aspecto ligado al primer ciclo. Ya en el segundo bloque se trabaja de manera más exhaustiva ya que el alumno debe ser capaz de identificar, percibir, describir y valorar lo que ve, y para ello debe apoyarse en una serie de herramientas y métodos como lo es la recogida y el análisis de datos, así como establecer relaciones y comparaciones. Para ello puede apoyarse en diferentes materiales y técnicas que el maestro debe introducir en su docencia como por ejemplo el trabajo con mapas topográficos, ortofotos, en el caso concreto del análisis de los paisajes rurales, el Mapa de Cultivos y Aprovechamientos agrarios, Atlas Agroclimático de Castilla y León, Google Earth, imágenes en diferentes periodos, etc....

El uso de estas herramientas va a permitir al alumno ser partícipe de los cambios del paisaje, ya que este no es estático, se transforma en el tiempo, tiene diferentes acepciones, expresiones y formas de representación, por ello se debe conseguir que comprendan los paisajes a través de diferentes estrategias mostrándoles diferentes tipos de representaciones del paisaje (dibujos, pinturas, descripciones literarias...) (Liceras, 2003, p.93).

El alumno no debe quedarse solo en lo descriptivo, es decir, en definir colores, formas, líneas, texturas, debe comprender lo observado y para ello debe establecer una búsqueda y relación entre los factores que se hayan observado. De esa manera será capaz de abordar satisfactoriamente durante el tercer ciclo, la fase de caracterización de los diferentes paisajes. 
En el marco de la LOMCE, la Orden ECD/686/2014, de 23 de abril, por la que se establece el currículo de la Educación Primaria se centra en aspectos concretos de cómo se puede trabajar el paisaje desde las diferentes disciplinas, como por ejemplo desde las Ciencias Sociales o la Expresión artística, a lo largo de la etapa. Los contenidos a los que hace referencia el currículo son: el paisaje natural; montaña y costa; elementos que forman el paisaje; tipos de paisajes; la intervención humana en el paisaje; respeto, defensa y mejora del paisaje; la diversidad geográfica de los paisajes naturales de España y de Europa; los Espacios protegidos; y temas de pintura en el paisaje.

Si bien es cierto que el tema del paisaje se puede y se debe trabajar de manera transversal desde las diferentes disciplinas de conocimiento, véase Delgado Huertos (2015, p. 120-123), son las Ciencias Sociales las que trabajan el tema del paisaje en profundidad. Según Liceras (2003, p. 13-14) el estudio del paisaje desde las ciencias sociales favorece el desarrollo de capacidades transversales ya que posibilita un análisis desde una perspectiva interdisciplinar (geografía, ciencias de la naturaleza, historia...); fomenta el desarrollo de valores fundamentales para la formación cívica de los alumnos; admite secuencias que pueden adaptarse al desarrollo psicoevolutivo de los estudiantes, desde los estadios de observación y clasificación hasta que son capaces de abordar sus propio procesos de investigación, toma de información, análisis, comparación, conclusiones; facilita al mismo tiempo la capacidad de abordar y comprender problemas sociales actuales y transcendentes y permite el desarrollo de las capacidades de percepción, descripción e interpretación del espacio geográfico y el disfrute del paisaje que le rodea.

El alumno debe ser capaz, por tanto, de reconocer los diferentes elementos del paisaje y las relaciones que los unen, reconocer la unicidad de cualquier paisaje, buscar una explicación de las características del mismo relacionadas con factores naturales y antrópicos, comprender las trasformaciones del paisaje y "contar su historia" (Castiglioni, 2010).

En definitiva, que sea capaz de hacer un análisis, interpretación y valoración del paisaje, es decir, "aunar la explicación y la comprensión, simultanear la vía de conocimiento apoyada en la razón y el pensamiento con la que utiliza el sentimiento y la imaginación como herramientas fundamentales" (Ortega Cantero, 2003 en Liceras, 2013, p. 92).

$\mathrm{Y}$ es en este aspecto donde juegan un papel importante las directrices que marcan las Órdenes por las que se establece el currículo de la educación primaria en las distintas Comunidades Autónomas ${ }^{3}$, en las que se fortalecen otros conocimientos sobre el paisaje donde entran en juego las escalas y la dicotomía local-global (Busquets, 2010).

3 Para Castilla y León puede verse la ORDEN EDU/519/2014, de 17 de junio, por la que se establece el currículo en Educación Primaria. 


\subsection{Cómo leer los paisajes}

En función del ciclo al que se dirija la propuesta la exigencia de la misma va a cambar. No es lo mismo una lectura del paisaje en los primeros ciclos, donde el alumno será capaz de visualizar los elementos que componen el paisaje y hacer una breve descripción del mismo, que en ciclos superiores donde el alumno ya tiene la capacidad para identificar, localizar, describir, analizar y explicar los elementos integrantes del paisaje que está estudiando.

Es posible, por tanto, que se divida la actividad de leer paisajes en dos momentos, el primero, la propia lectura del paisaje y posteriormente un análisis y comprensión del mismo. En el siguiente cuadro se hace una síntesis de las tareas a realizar en cada momento:

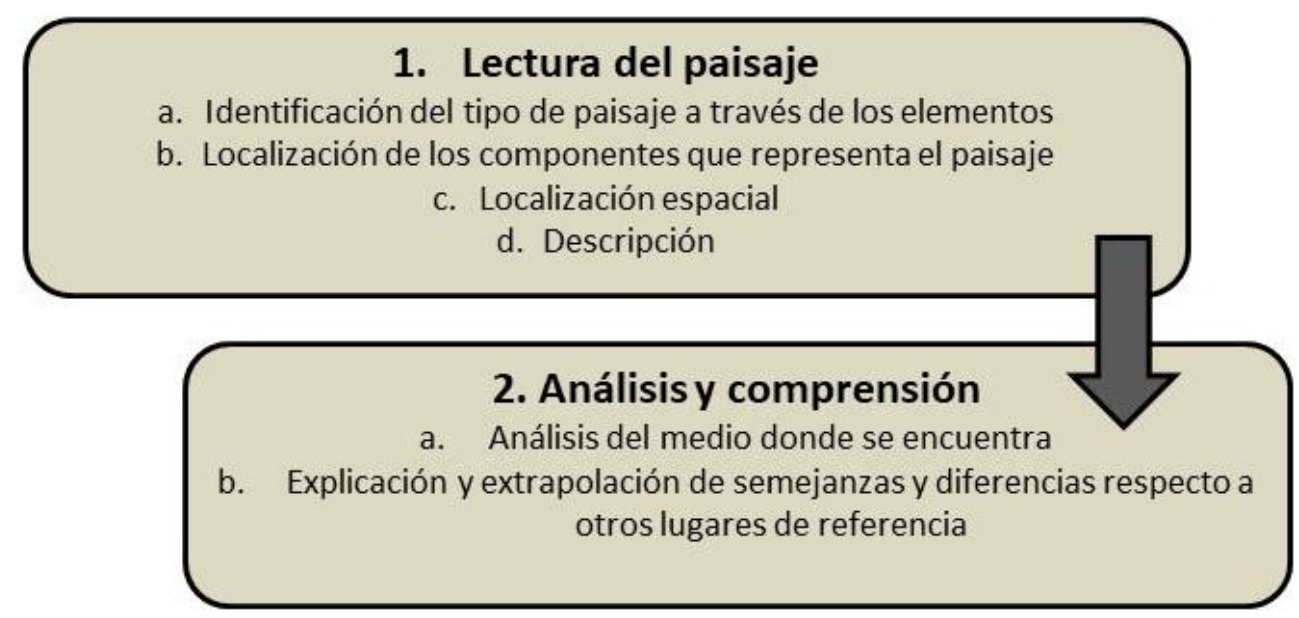

FiguRA 1. Pasos para la lectura del paisaje. Fuente: Adaptación de Liceras Ruiz, 2003.

La observación es clave, tiene un interés didáctico-formativo "porque es un procedimiento básico que precede y posibilita el uso de otros recursos para la apreciación y el conocimiento de las realidades y relaciones espaciales" (Liceras Ruiz, 2003, p. 103).

Cuando realizamos observación directa, que implica el trabajo de campo, fuera del aula, en contacto con los elementos visibles del paisaje y la percepción a través de los sentidos, mediante la cual se aprecian los sonidos, el movimiento, los olores y al mismo tiempo, se pueden establecer relaciones entre los fenómenos que lo ocasionan o las repercusiones en el paisaje. Por otro lado, cuando se trabaja mediante la observación indirecta, en la propia aula, nos acercamos a los paisajes a través de imágenes, fotografías, música, relatos, obras de arte... 
Ambas maneras requieren una preparación previa, la observación directa exige el conocimiento del espacio sobre el que se va a trabajar, la preparación de los materiales a emplear en la observación, la selección de cartografía e imágenes, la elaboración del dosier de la salida. Por su parte, la observación indirecta implica la utilización de cartografía (mapas topográficos) el visionado y la selección de imágenes (fotografía y vídeo), de piezas musicales o textos, requiere un tratamiento didáctico, y nos permite mostrar a los alumnos realidades lejanas y establecer relaciones entre las mismas.

La utilización de estos recursos en el aula permite observar y analizar todos los elementos que integran un paisaje pudiendo establecer la diferencia entre los elementos abióticos (relieve, litología), bióticos (masas forestales, fauna y vegetación) y antrópicos (poblamiento, cultivos, ganadería, industria, turismo, segunda residencia, etc.) y sus relaciones e interdependencias.

\subsection{Qué aprendizajes significativos aporta el paisaje}

En la idea de la utilidad pedagógica del paisaje Tort (2004, p.135) lo considera una "herramienta multidisciplinaria" capaz de proporcionar, por su dimensión sintética, una comprensión integral e integradora de todo lo que acontece en nuestro entorno". Desde el punto de vista didáctico el estudio del paisaje puede contribuir a "mejorar las aptitudes cognitivas del individuo, ya que favorece el aprendizaje autónomo y activo, la construcción de conceptos, la adquisición de conocimientos reales y la orientación de experiencias y percepciones que median y contribuyen a la formación de los alumnos" (Liceras Ruiz, 2003, p. 103).

La práctica de la observación a la que se hacía referencia anteriormente permite a los alumnos progresar en la capacidad de adquirir aprendizajes nuevos, pero al mismo tiempo, contribuye a establecer una relación entre los fenómenos que se observan, y establecer una relación de causa-efecto entre ellos.

Al mismo tiempo, el paisaje como eje transversal de conocimientos contribuye, saltando por encima del encasillamiento de los saberes, a trabajar otras disciplinas permitiendo el uso en el aula de un currículo multidisciplinar (educación artística, literatura, lengua, matemáticas....) y que se puede asociar a un espacio concreto, como es el ejemplo de la comarca de Tierra de Campos y los municipios objeto de estudio, que se verán más adelante.

\section{UN PROYECTO DE PAISAJE EN LA TIERRA DE CAMPOS}

El presente proyecto tiene por objeto utilizar dos municipios de la comarca de Tierra de Campos, Torremormojón (Palencia) y Villalón de Campos (Valladolid), 
elegidos por constituir dos ejemplos significativos del paisaje rural de esta comarca. Estos municipios están separados por poco más de 30 kilómetros, lo que facilita el desarrollo de una salida de un día completo. Por otra parte, presentan características muy acusadas de los dos modelos extremos de ocupación del territorio terracampino: por un lado, Torremormojón es un municipio localizado en las estribaciones de los Montes Torozos, con menos de 100 habitantes, y severos problemas de despoblación; y, por otro, en Villalón, localizado en la campiña, encontramos el caso de un núcleo de referencia comarcal que, pese al retroceso demográfico, todavía mantiene un peso específico en el territorio.

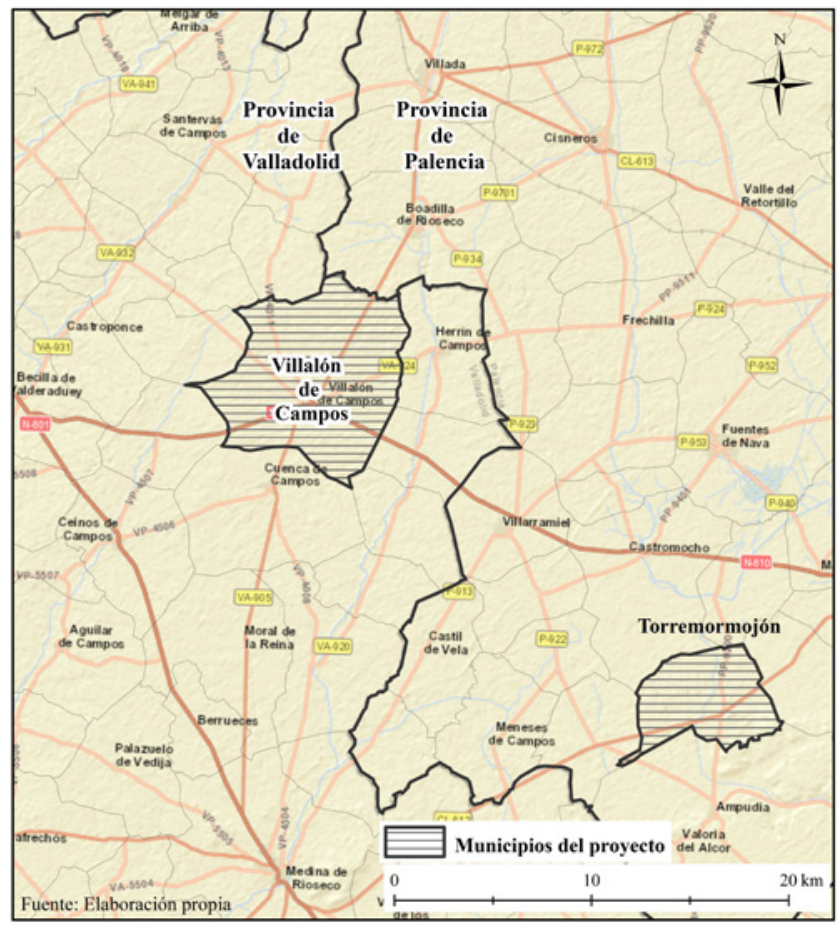

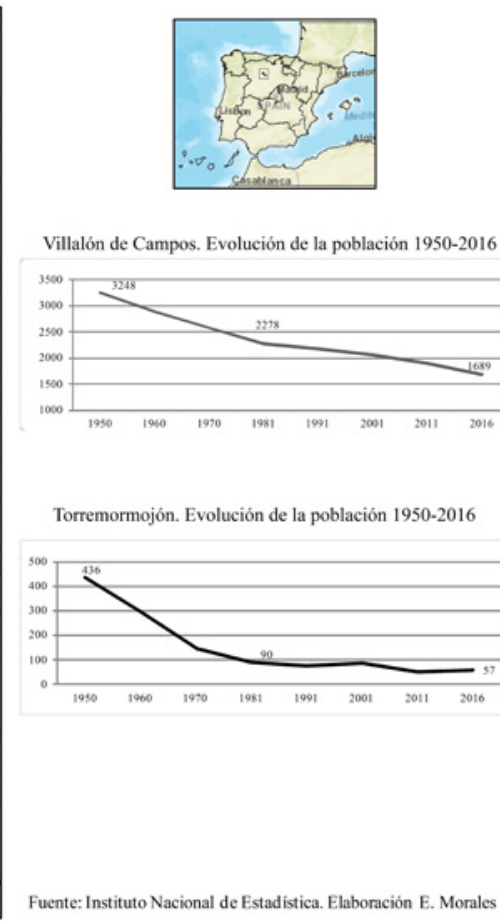

Fuente: Instituto Nacional de Estadistica. Elaboración E. Morales

FiguRA 2. Mapa de localización y evolución de la población de los municipios objeto de estudio. Escala 1:500.000

El estudio de estos casos no solo va a permitir hacer una propuesta de actividad ligada a un paisaje rural concreto, sino a que a partir de esta lectura, el alumno va a ser capaz de comprender los principales rasgos que caracterizan al medio rural del centro de la cuenca del Duero. 


\subsection{Aproximación a los elementos significativos del paisaje de la comarca}

La comarca de Tierra de Campos se extiende por las provincias de Palencia, Valladolid, León y Zamora, ocupando una superficie ${ }^{4}$ de $5.820 \mathrm{~km}^{2}$. Un vasto territorio donde perviven espacios agrarios, ganaderos, rurales y urbanos, adaptados a la propia morfología constituida por campiñas (llanuras suavemente onduladas) limitadas por los páramos detríticos al norte y los calcáreos al sur (Vaca, 1992).

Un paisaje determinado por las propias características del clima, netamente continental con inviernos frescos y fríos y veranos cálidos, lo que "tiene unas fuertes repercusiones sobre la arquitectura tradicional, como la necesidad de construir muros de gran espesor para hacer frente a estas variaciones mediante la inercia térmica" (Cortés, 2014, p. 49) y con usencia de precipitaciones, las cuales oscilan a lo largo del año entre los 400-450 $\mathrm{mm}$ anuales.

Este aspecto condiciona la red hidrográfica, entre la que se distinguen tres cauces de mayor caudal como son: el Cea (que discurre por las provincias de León, Valladolid y Zamora), el Carrión a su paso por la provincia de Palencia y, el Pisuerga que atraviesa tierras palentinas y vallisoletanas, aunque existen otros cauces menores, mas irregulares y de carácter estacional como el Sequillo (afluente del Valderaduey, su curso entra en contacto con las cuatro provincias que alberga Tierra de Campos), el Valderaduey (afluente del Duero), Valdeginate, Cueza y Ucieza entre otros a los que hay que sumar una intermitente red de arroyos.

Una red hidrográfica íntimamente relacionada con los humedales de Tierra de Campos, una red de lagunas y charcas endorreicas como las Lagunas de la Nava, Boada, Villafáfila y de los Oteros. Destaca el Canal de Castilla cuyo tramo central y el Ramal de Campos atraviesan la comarca dejando a su vera un rosario de lagunas, también incluidas en la Red Natura 2000.

La vegetación dominante, refugiada principalmente en los páramos, la constituyen los bosques de encina (Quercus ilex) y quejigo (Quercus faginea), las repoblaciones en las laderas de pino carrasco (Pinus halepensis); y estrechas franjas de vegetación ripícola en las riberas de ríos y arroyos, frente al predominio del paisaje agrícola cerealista.

Un paisaje que cuenta con la presencia de pequeños núcleos compactos, distantes entre sí por 5 a $10 \mathrm{~km}$., donde predomina la arquitectura tradicional de Tierra de Campos ${ }^{5}$, lo que Benito (1998, en Blanco et al, 2016) define como "núcleos en origen cercados, de

${ }^{4}$ García, L. (Coor.), (1988), Análisis del medio físico (Valladolid y Palencia). Junta de Castilla y León. Consejería de Fomento.

5 Para este apartado es útil el libro "Estudio de la tipología arquitectónica y urbanística en el medio rural de la provincia de Valladolid" Sainz Guerra (Coor) que está disponible en internet. https://www5.uva.es/grupotierra/publicaciones/digital/librotipologias/librotipologias.pdf 
disposición continua y edificación con corral posterior", que usa como materiales básicos el barro, la madera y la teja curva árabe. Además, resaltan otros elementos singulares que caracterizan el paisaje arquitectónico de Tierra de Campos y forman parte de sus señas de identidad, tales como los palomares, los castillos y la arquitectura monumental religiosa, de la que encontramos ejemplos en la mayoría de los pueblos, que cuentan con una o varias iglesias de estilo románico, gótico y/o renacentista, con la singularidad de sus variantes mudéjares, que destacan entre el caserío (Blanco et al., 2016). Como dice Baraja (2011, p. 230) "ruina y escombro conviven con nuevos elementos que responden a un perfil no definitivamente asentado: los pobladores que se quedaron, con más recursos, sustituyen o modernizan el caserío utilizando materiales modernos, más consistentes, pero también menos armoniosos"

Un paisaje rural afectado por la masiva salida de población, desde 1950, como consecuencia del modelo productivista basado en la alta mecanización de las labores del campo, que cada vez necesita menos mano de obra, lo que ha dado lugar a un espacio despoblado y, abocado a la desaparición de cuantiosos núcleos de población.

Sin embargo, es un espacio con un alto valor paisajístico, de ahí que se haya seleccionado como objeto de estudio para el presente trabajo.

\subsection{El municipio de Torremormojón}

Situado en el suroeste de la provincia de Palencia, este pequeño municipio ocupa una superficie de 2.824 Ha y tiene poco más de 50 habitantes $\left(2 \mathrm{hab} / \mathrm{km}^{2}\right)$. Se localiza a los pies de los montes Torozos y, por tanto, su término municipal se distribuye entre los páramos situados a una altura de $860 \mathrm{msnm}$, las cuestas y las lomas y campiñas donde se encuentra el núcleo, emplazado a una altura de $778 \mathrm{msnm}$. Los arroyos de Arenales y del Salón, afluentes del Valdeginate, atraviesan la llanura de sur a norte a más de 500 metros del casco. Torremormojón se encuentra integrada en la Mancomunidad de Alcor de Campos, constituida en 1992, por un total de siete municipios con el fin de compartir, entre otros, servicios tales como la recogida de basuras, la potabilización y el abastecimiento de agua a la localidad, que permiten que estos municipios cuenten con unas dotaciones que de manera independiente no sería viable.

El casco cuenta con tres elementos relevantes desde el punto de vista del patrimonio cultural: la iglesia de Santa María del Castillo, que se levanta en la segunda mitad del siglo XII y va ampliándose hasta el siglo XVIII, ha sido declarada monumento histórico artístico; el pósito, donde primeramente estuvo el convento de Santa María de la Piedad, siglo XVII, hasta la marcha de las monjas a la ciudad de Palencia, albergó el granero municipal y en la actualidad aloja el centro cultural, tras su rehabilitación en 2017. Finalmente es reseñable la importancia, pese a su abandono, de los 23 
palomares inventariados por Manuel Malmierca (2009, p. 247-255) y localizados tanto en los bordes como en el propio casco urbano o diseminados en el término municipal.

Fuera del casco, el interés se centra en las ruinas del Castillo, cuya construcción original se remonta al siglo XII y fue reconstruido a comienzos del siglo XVI. Es de planta cuadrada con grandes cubos en las esquinas y una torre protegiendo la entrada. Todo el frente es de sillería, con muros de cuatro metros de grosor y troneras para la artillería. El castillo tuvo un foso defendido a través de muchas cámaras de tiro que estaban comunicadas por una galería intramuros. Esta galería estuvo ocupada por un inmenso palomar, hoy abandonado, del que se conservan las oquedades o garitas. El Castillo se intercomunicaba visualmente con los castillos de Paradilla del Alcor, Ampudia y Montealegre.

El cerro sobre el que se levanta el Castillo ha conocido una repoblación con pino carrasco (Pinus halepensis) al igual que las laderas del páramo contiguo, El Castre, donde se ha instalado el Parque Eólico del mismo nombre, que ha ido creciendo desde los 16 aerogeneradores con los que se puso en marcha.

Como parte del Plan de mejoras en el entorno, desarrolladas en paralelo a la instalación del parque eólico, se ha señalizado y dispuesto paneles informativos sobre flora, fauna, historia, etc.); se han realizado repoblaciones con especies autóctonas y ornamentales (almendros, retama olorosa o gayomba, ciprés común, acacia de tres espinas, tamarisco, tuya gigante, fotinia de hojas rojas, sauce tortuoso, etc.); se han construido diques de madera para paliar la escorrentía y la erosión superficial y se ha mejorado la pista de acceso al Castillo.

\subsection{Villalón de Campos}

El municipio de Villalón de Campos se localiza en el norte de la provincia de Valladolid, a unos $70 \mathrm{~km}$. de la capital provincial. El término municipal tiene una superficie de 7.033 Ha. Y una población cercana a los 1.700 Habitantes (INE, 2016), con una densidad de población de $24 \mathrm{hab} / \mathrm{Km}^{2}$.

Al igual que Torremormojón, parte de su término municipal pertenece a la Red Natura 2000 y está integrado dentro de la Zona de especial protección para las aves (ZEPA) denominada La Nava - Campos Norte.

A una altitud entre los 750 a 800 metros sobre el nivel del mar, su relieve es predominantemente ondulado sobre suelos arcillosos donde predominan los cultivos cerealistas que caracterizan a toda la comarca. La economía, además de los servicios propios de un centro comarcal, está basada en la agricultura y la ganadería, donde se inscribe la presencia de una cabaña ganadera, fundamentalmente aviar, pero en el que destaca el ganado ovino que, aunque en progresivo retroceso, aún mantiene un importante 
número de cabezas (GAMA, 2004: 5) ${ }^{6}$, lo que ha otorgado al municipio de Villalón un protagonismo específico en lo que a industria alimentaria se refiere, por la elaboración de quesos frescos "Pata de mulo".

El mercado constituye otro de los elementos principales para explicar la importancia de esta villa, desde que Fernando II le otorgase el mercado que se viene celebrando desde 1250. Momento clave en el que las ferias adquirieron un gran protagonismo, habiéndose convertido en uno de los mercados financieros de Europa, durante parte de los siglos XV y XVI. Un mercado destinado al abasto y avituallamiento, así como a la compra-venta de ganado, herramientas, utensilios...convirtiéndose la plaza en el centro neurálgico y de negocios de la villa. Una plaza caracterizada por estar rodeada de soportales porticados donde se instalaban los comerciantes que llegaban desde diferentes ciudades españolas, y también del extranjero. Cada comerciante tenía su sitio y su porqué. De ahí que las calles colindantes recibiesen, y aun en la actualidad se mantenga, el nombre de los oficios asentados. Por ejemplo, la calle Marceliano Serrano, anteriormente llamada "La Zapatería", albergaba a los libreros y borceguileros (zapateros). En la Plaza de San Juan se exhibían las ovejas; en la calle Santo Domingo el aceite, la cera y el sebo de los portugueses. En la calle Costanilla, junto a la Puerta de San Miguel, el pescado de Cantabria, etc...

Al mismo tiempo, además de los soportales, el casco histórico mantiene la arquitectura tradicional de una villa con caserío concentrado, con calles adoquinadas, con soportales y casas construidas con los materiales propios de Tierra de Campos, como el adobe y ladrillo, entre las que son reseñables las casas blasonadas localizadas en las calles Calvo Sotelo, Olmillo y del Otero (PGOU, 1991). Con una plaza central que cuenta con mucho del protagonismo de la villa, no solo porque en ella tenía lugar el ya citado mercado o las ferias, sino que en torno a ella se elevan los monumentos más característicos tales como la Iglesia de San Miguel, de estilo gótico-mudéjar de los siglos XIII y XIV y el Rollo Jurisdiccional, alzado en 1523 y declarado Monumento Nacional, de estilo góticoisabelino, de unos diez metros de altura y con un elevado valor arquitectónico.

Además de mantener el carácter tradicional en calles y viviendas, dentro de un modelo urbano extensivo (PGOU, 1991, p. 4), Villalón ha experimentado una pequeña expansión urbana en los años 1990 con el desarrollo de urbanizaciones de viviendas unifamiliares ubicadas al suroeste del municipio, que siguen el patrón de las levantadas en los bordes de las ciudades.

${ }^{6}$ El Censo Agrario de 2009 cifraba en 1532 las cabezas de ganado ovino en Villalón. INE. 


\section{METODOLOGÍA, CONTENIDOS DEL PROYECTO Y PROPUESTA DE ACTIVIDADES}

\subsection{Metodología}

La propuesta que aquí se presenta no se ha llevado a la práctica y, por ello, no es y no puede ser cerrada. Se pretende aportar al profesorado una serie de ideas sobre cómo se puede implementar un proyecto de trabajo que tiene como centro de interés un paisaje rural en Tierra de Campos, en el que se incluye una salida.

Se enmarca esta propuesta en un proyecto, que se diferencia conscientemente de actividades aisladas y descontextualizadas con las que muchas veces se tratan las salidas del aula y que no permiten un aprovechamiento integral de las mismas, más allá del componente puramente lúdico. Por el contrario este proyecto permite utilizar métodos pedagógicos diversos, hace posible la puesta en práctica de un amplio abanico de actividades e introduce una perspectiva de conjunto que reduce el problema de la pérdida de objetivos

El proyecto trata de utilizar una comarca rural de considerable extensión, en franco declive demográfico, que conserva un alto interés patrimonial, con unas formas de hábitat muy características, y un modo de organización y aprovechamiento del territorio que deben ser protegidos porque forman parte de la esencia del centro de la cuenca del Duero, para hacer discurrir todos los elementos constitutivos y relevantes de la comarca y presentar las interrelaciones más importantes que se producen entre ellos.

La salida, siguiendo las fases de preparación, realización y reflexión y trabajo en el aula descritas por Delgado y Alario (1994, p. 161-164), ha de ser planificada por el profesorado responsable quien será el encargado de materializar la propuesta en cada una de las fases enunciadas y participada por el grupo de escolares, tanto por lo que se refiere a la organización logística de la salida como a la selección de los contenidos y las visitas a desarrollar durante la misma.

Así pues, lo que se sugiere aquí puede ser llevado a la práctica o usado parcialmente, ya que serán las características del grupo y los objetivos que se persigan los que determinen los contenidos y las actividades a desarrollar en el proyecto y el formato del dosier de la salida.

De manera orientativa se han señalado aquellas actividades que entendemos más propias de aula que para ser realizadas durante la salida, y que conllevan el uso de otras fuentes y herramientas para el conocimiento de estos paisajes rurales. No se trata de una salida en la que un guía o el propio profesor son los responsables únicos de las explicaciones, en este caso lo que se pide es que el alumno sea el protagonista de la búsqueda de información relativa a los municipios a visitar. 
La salida tiene una duración prevista de una jornada $(9,00$ a 18,00 h.) de las que se emplearán entre dos y tres horas en cada localidad, incluyendo el tiempo dedicado al almuerzo y la comida.

Se trata de que los escolares se familiaricen con una serie de herramientas (fotografía, mapas, dibujo, cuaderno de campo) y procedimientos (paseo indagatorio, entrevistas, visitas a museos, consultas en internet) que les serán útiles no solo para descubrir el paisaje de Tierra de Campos, sino también para establecer relaciones con diferentes ámbitos rurales.

De esta manera nos centramos en presentar una serie de actividades orientativas a desarrollar en el aula y durante la salida de campo que forman parte del cuerpo central del proyecto al que hemos hecho referencia.

\subsection{Torremormojón. Sugerencias didácticas y actividades}

En esta localidad realizaremos, en primer lugar, una visita al núcleo, sus calles, su perímetro exterior, sus edificios, para, posteriormente, subir al Castillo y obtener una perspectiva completa del núcleo y su entorno. Es conveniente que los escolares tengan contacto con algún representante municipal o algún vecino al que poder formularle las preguntas que hemos planteado en el cuestionario. Podría solicitarse el uso del Centro cultural, para celebrar el encuentro.

\subsubsection{Una mirada}

- Anota en tu cuaderno de campo todo aquello que te sugieran términos como despoblación, abandono, aislamiento, ruina, ausencia, decadencia.

- Con la cámara recoge imágenes que relaciones con estos conceptos.

\subsubsection{Un elemento de primera necesidad}

- ¿Qué río o qué arroyo pasa por Torremormojón? ¿Cómo se llama?

- ¿A qué Mancomunidad pertenece el municipio de Torremormojón? ¿Qué servicios le proporciona?

- ¿De dónde se abastece de agua la población?

- ¿Hay problemas de abastecimiento en el pueblo?

- ¿Hay depósito de agua potable, dónde se encuentra?

- ¿Cómo se depuran las aguas residuales? 


\subsubsection{De los elementos del paisaje}

- Identifica e intenta localizar los bloques o fardos de paja apilados ¿Cómo se denominan?

- ¿Para qué se utilizaba y se utiliza la paja? (Aula)

- Identifica y localiza los corrales de las casas, ¿qué función tenían y tienen?

- Leemos el artículo de Elisa Sánchez "Los palomares en la Tierra de Campos Palentina " y averiguamos cómo se denominan las partes de un palomar (Aula)

- En el cuaderno de campo dibuja uno o más palomares.

- Un aerogenerador sirve para producir energía eléctrica, identifica las partes que lo componen (Aula)

- ¿Por qué crees que se instalan aerogeneradores en esta zona de Tierra de Campos? (Aula)

- Nos informamos ¿en qué consiste la concentración parcelaria? (Aula)

- La ganadería de ovino ha sido muy importante en Tierra de Campos. Esta actividad ganadera se sigue viendo en los rebaños de ovejas que pastan en los campos, pero también ha dejado múltiples rastros en el paisaje entre los que destacan los corrales y las fuentes. En la Hoja 311 del MTN a escala 1/50.000, que lleva el nombre de la localidad de Dueñas, o en la Hoja 311-I del MTN a escala 1/25.000, denominada Pedraza de Campos, en las que está incluido el término municipal de Torremormojón, realizar, por grupos, un inventario de las fuentes y los corrales que aparecen en la toponimia de estos mapas (Aula)

\subsubsection{El Pósito}

- ¿Qué era un pósito, también llamado alhóndiga, para qué servía? (Aula)

- ¿De quién dependía?

- ¿Por qué era importante para los habitantes del núcleo?

- ¿En qué se ha convertido en la actualidad?

- ¿Qué otros usos ha tenido?

\subsubsection{Dos edificios, dos formas constructivas}

- Utiliza los términos que corresponden a cada uno y los escribes sobre las fotos.

o Ayuntamiento (sillares, sillarejos, ladrillo, campanil, teja árabe)

o Una casa reformada (revocado, dintel, mampostería, cornisa) 
Los paisajes rurales en los proyectos educativos de enseñanza primaria. Una propuesta ...

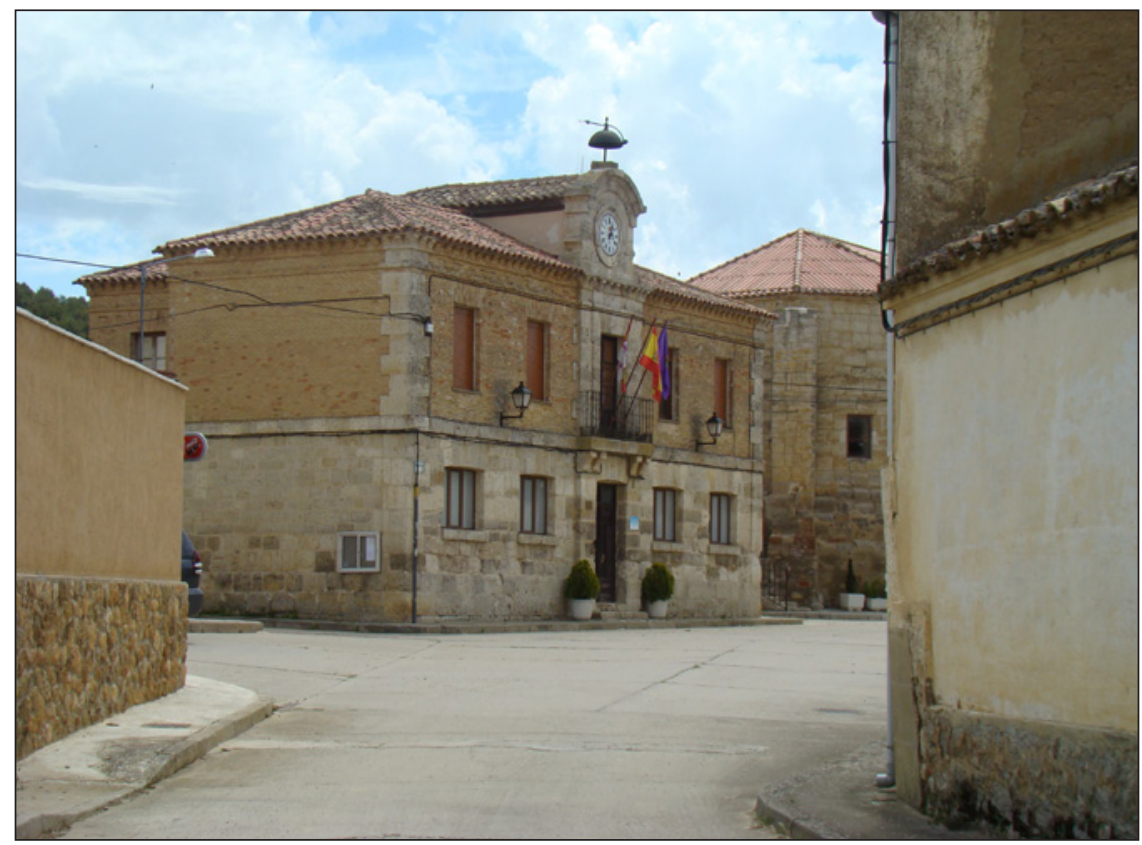

FIGURA 3. Torremormojón. Ayuntamiento. Foto: E. Delgado

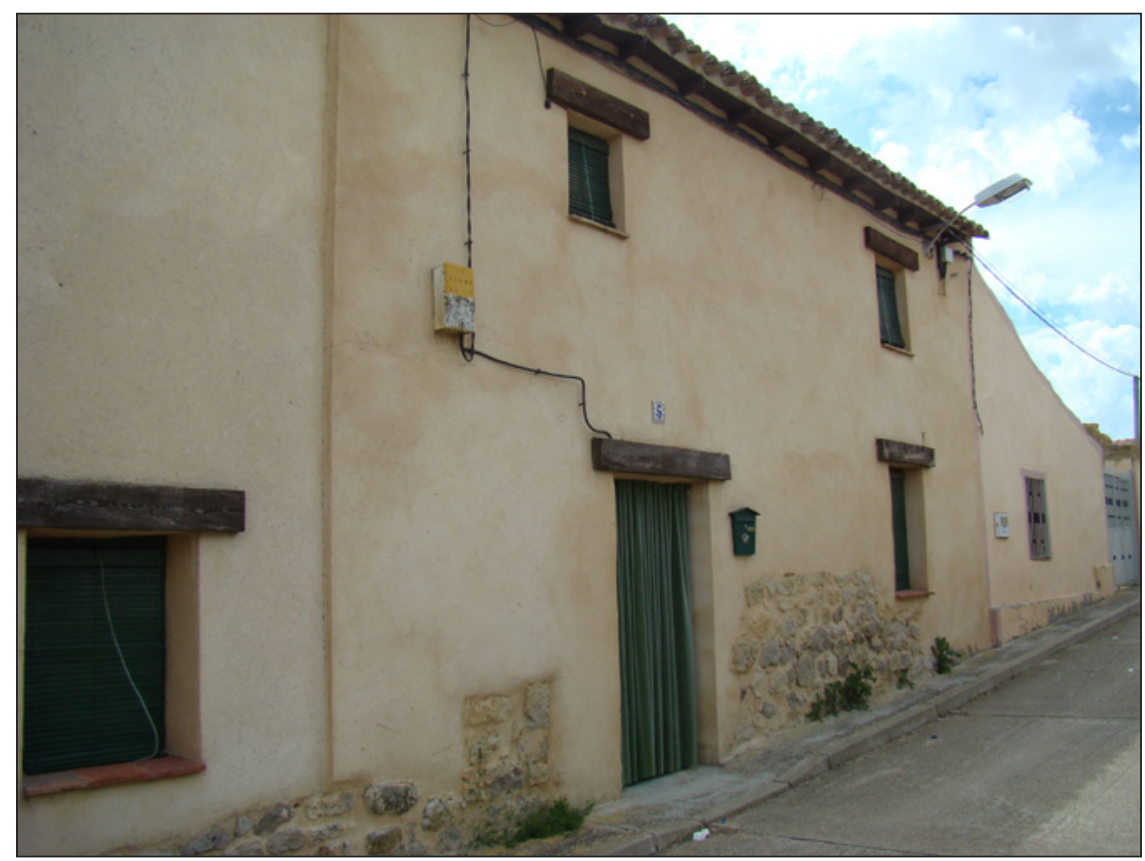

Figura 4. Torremormojón. Casa reformada. Foto: E. Delgado 


\subsubsection{Las tierras cultivadas}

La información relativa al paisaje agrario puedes obtenerla mediante la observación directa o a través de algún vecino del pueblo. También si consultas la Wikipedia de Torremormojón. (Aula). Además puedes consultar otras herramientas como el Atlas Agroclimático de Castilla y León a través del visor http://atlas.itacyl.es/visor y a partir de ahí, responder las siguientes preguntas:

o ¿A qué se destina de forma predominante la superficie cultivada?

o ¿Cuáles son las diferencias entre un cultivo de secano y uno de regadío?

\subsubsection{El Castillo}

El Castillo es Monumento Histórico-Artístico desde 1878 y ha sido incluido en 2008 en la Lista Roja de Patrimonio en Peligro. Es conocido como La Estrella de Campos. Se localiza en un cerro en las estribaciones de los Montes Torozos.

- Mira atentamente el mapa de Torremormojón y responde a estas preguntas ¿A qué altitud se encuentra el Castillo? ¿Cuántos metros por encima de la iglesia y del cementerio? ¿Qué distancia hay entre el Castillo y el cementerio? (Aula)

- ¿Cuántas torres le quedan al Castillo?

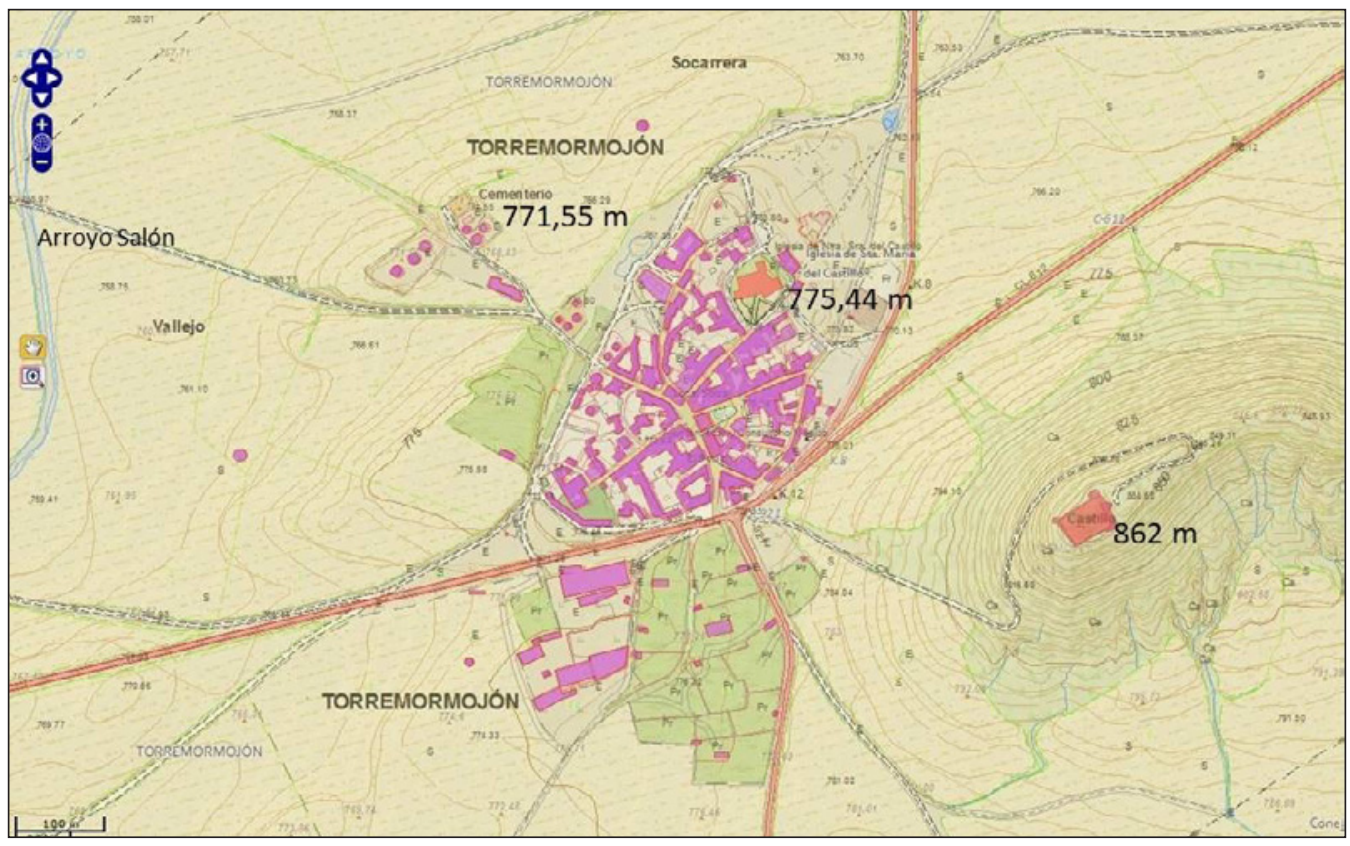

FiguRA 5. Torremormojón. Fuente: IDECyL. 
- Las marcas de cantero son símbolos o signos grabados por los canteros en la piedra. ¿Has visto alguna de estas marcas? Toma el cuaderno de campo, ponlo encima de la marca y frota cuidadosamente con lápiz o carboncillo, te llevarás la firma del cantero.

- Te habrás fijado que en los muros de la muralla del Castillo aparecen unos huecos a uno y otro lado del angosto pasillo o galería que los separa. ¿Para qué crees que sirvieron?

- ¿Con qué materiales está construido el Castillo?

\subsubsection{El paisaje desde el mirador del Castillo}

- ¿Qué elementos naturales observas?

- ¿Qué elementos del núcleo urbano te llaman la atención?

- Como parte de las casas están los corrales ¿Cuántos ves?

- ¿Cuántos edificios en ruinas y cuántos nuevos se observan en el casco de Torremormojón?

- Y las manchas blancas del tejado de la torre de la iglesia ¿a qué crees que se deben?

- ¿Se ve maquinaria o aperos agrícolas?

- ¿Cómo son las parcelas, qué forma tienen?

- ¿Qué otros aprovechamientos humanos se ven?

- ¿Cómo se llama el Parque eólico?

- ¿Qué especie de pino se ha utilizado para repoblar las laderas?

- ¿Qué colores identificas y a qué actividades o aprovechamientos pueden estar asociados?

- Con ayuda de un mapa y una brújula, ¿qué otros núcleos se observan?

- Si el día está claro se ve el castillo de Ampudia, ¿lo puedes localizar?

- Esta es la estructura y la fotografía del paisaje del valle interior entre el Castillo y el Parque eólico. Escribe sobre el dibujo los elementos que caracterizan cada una de las partes en que se ha subdividido el paisaje que se observa.

- ¿Qué es lo que te gusta?, ¿qué es lo que te agrada de este paisaje de Tierra de Campos que se contempla desde el Castillo? ¿Qué es lo que no te gusta?

- Con pintura de dedos recrea a tu manera, en el cuaderno de campo, el paisaje que observas.

- ¿Qué echas en falta en este paisaje? ¿Cómo podríamos mejorarlo? Con un lápiz haz tu propia intervención de mejora en esta fotografía. (Aula) 


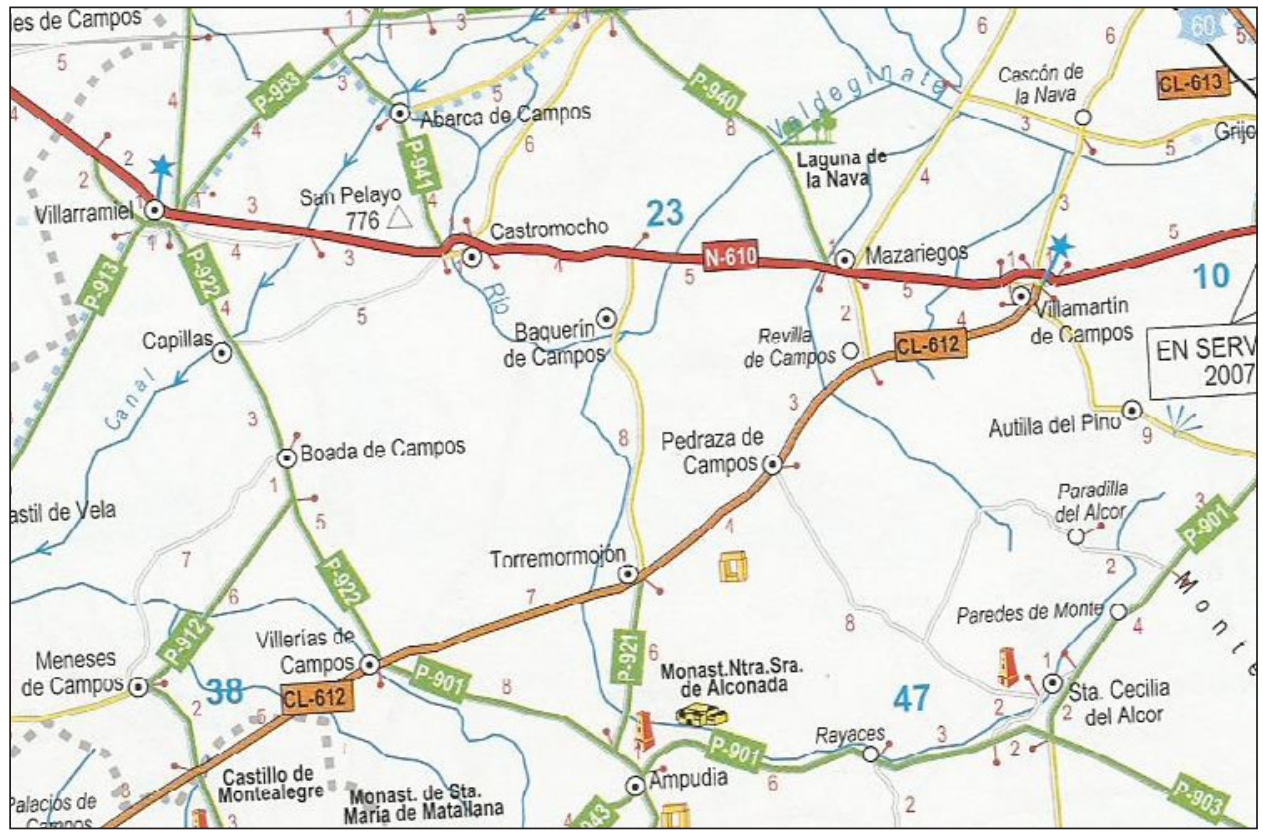

Figura 6. Fuente: Mapa Oficial de Carreteras. Ministerio de Fomento.

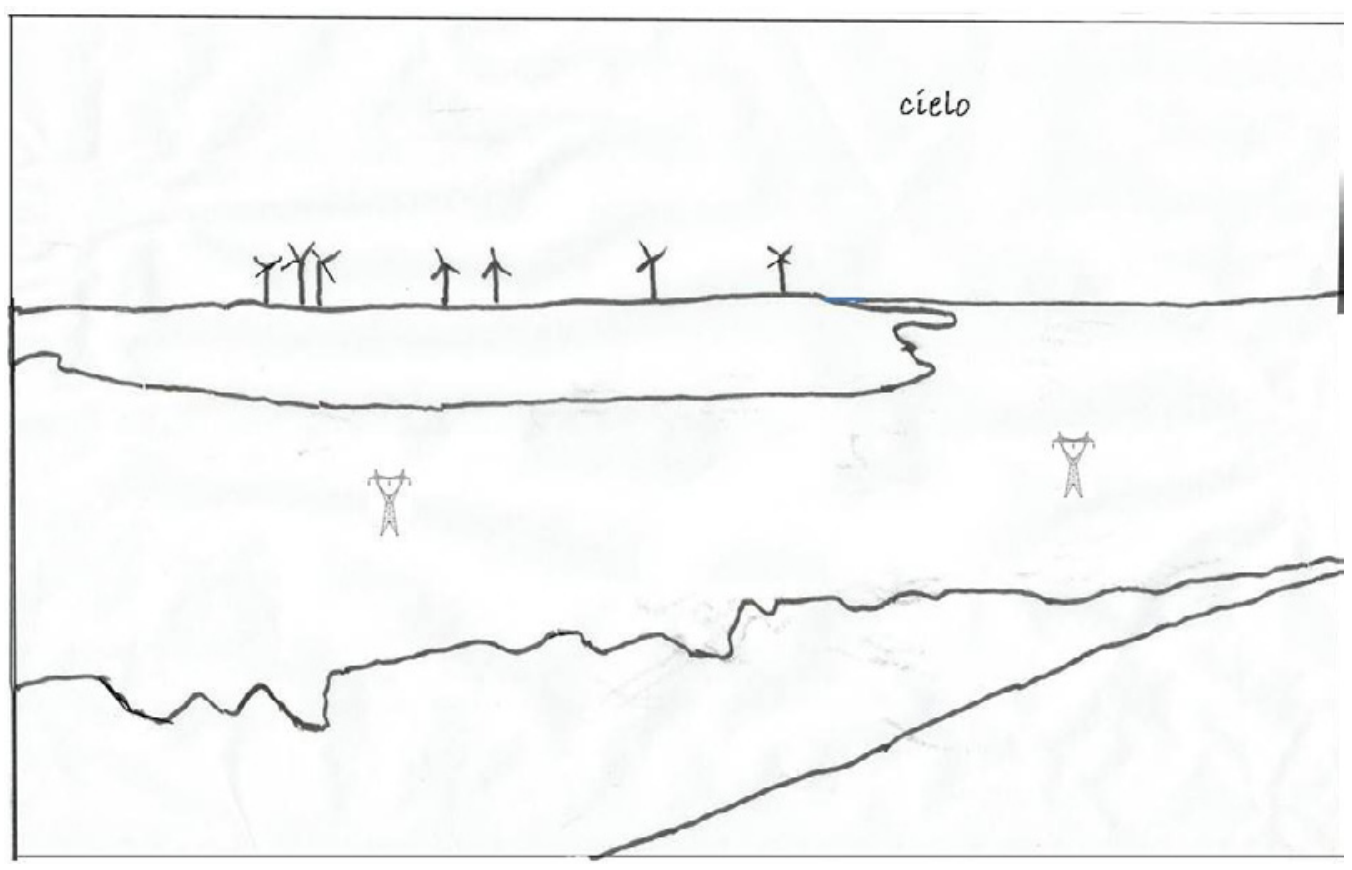

FIGURA 7. Estructura del paisaje. Elaboración propia 
Los paisajes rurales en los proyectos educativos de enseñanza primaria. Una propuesta ...

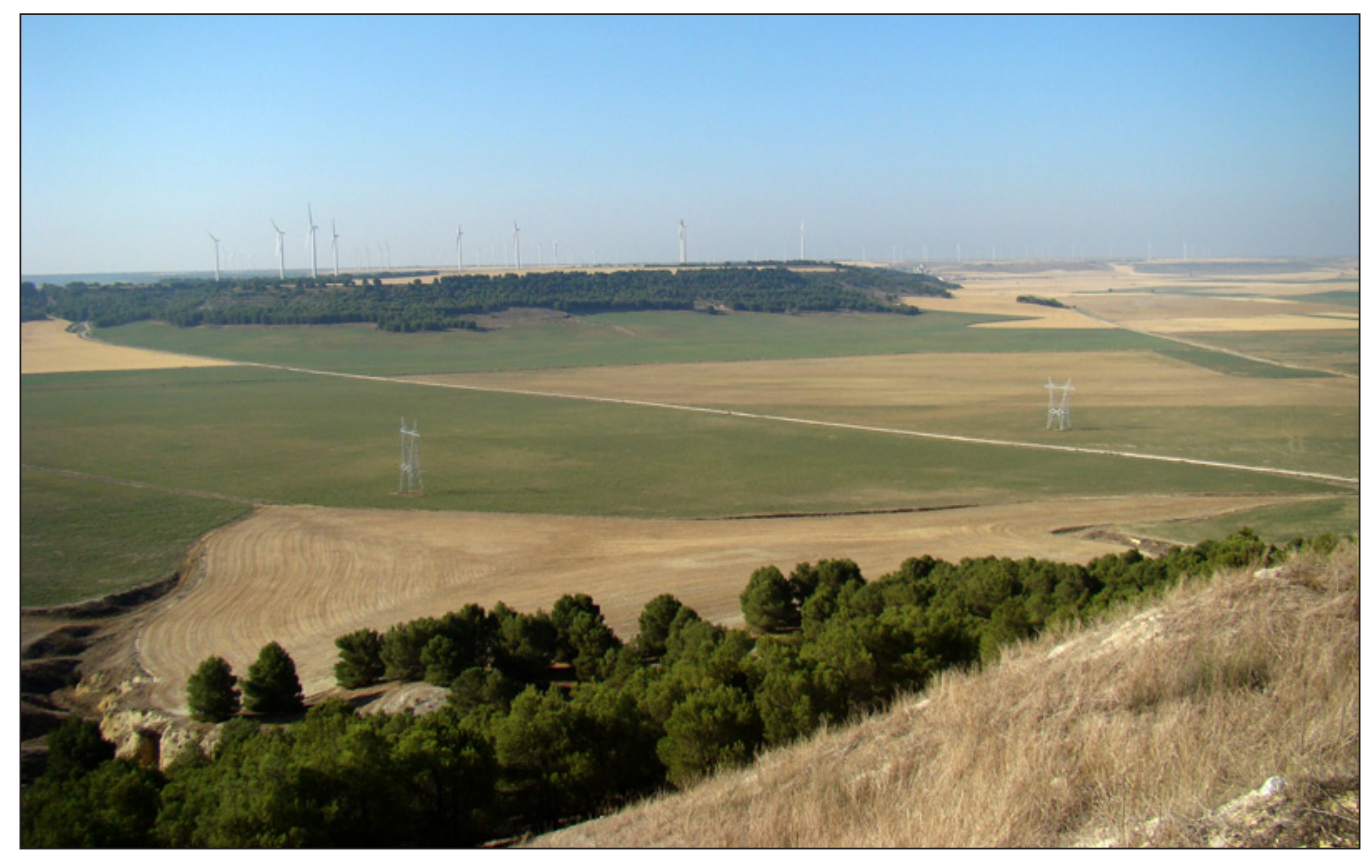

FIGURA 8. Torremormojón. Vista del valle interior. Parque eólico de El Castre. Foto: E. Delgado

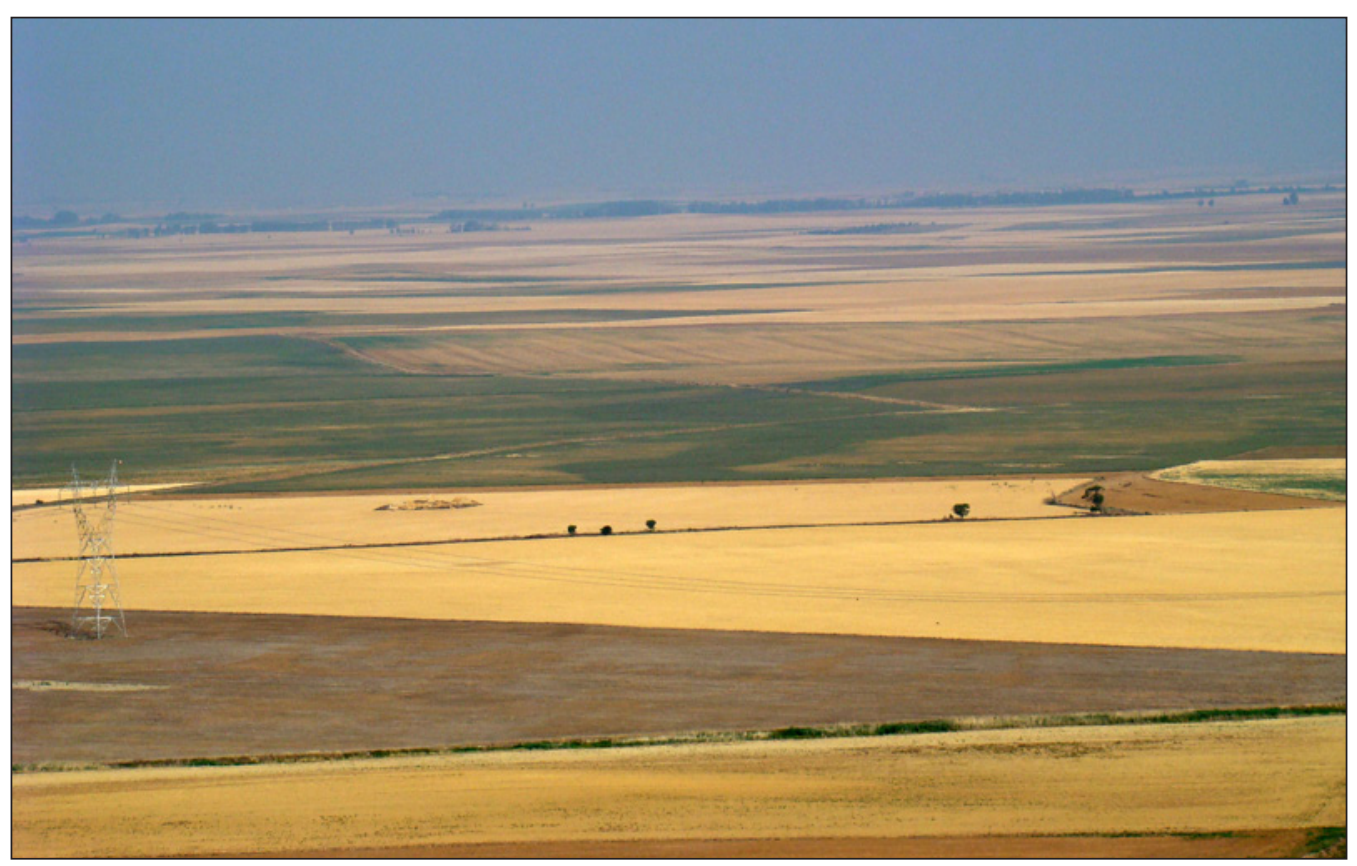

FIGURA 9. Vista hacia el noroeste desde el Castillo de Torremormojón. Foto: E. Delgado 


\subsection{Villalón de Campos. Sugerencias didácticas y actividades}

Se considera muy importante que los escolares no se limiten a tener un contacto puntual con los distintos centros de interés que se proponen en la visita. Es conveniente que recorran el pueblo, conozcan de primera mano sus calles, su arquitectura culta y popular, vean con sus ojos la actividad económica que se desarrolla, entren en los parques y zonas ajardinadas de la Ruta de los Parques, etc. Al margen de que se puede incluir la visita a la Fábrica de Quesos “La Quesera de Villalón”, al Museo del Queso, al Palomar del Abuelo o al Museo de los Aperos de Labranza, sería provechoso concertar un encuentro-foro con los escolares del mismo curso del CPC "Tierra de Campos" a fin de que el grupo conozca directamente las vivencias de estos escolares en el entorno rural y pueda producirse un intercambio de experiencias.

\subsubsection{La importancia de los soportales}

- Bajo los soportales ¿qué actividad se realizaba? Establece una relación entre las calles colindantes y la actividad/ oficio que se realizaba.

- ¿Por qué son tan importantes y existen tantos tramos de soportales en Villalón?

- Los pilares y los postes de pie derecho de los soportales: anotamos los distintos materiales con los que están hechos

\subsubsection{El queso de Villalón ha tenido y tiene un gran valor económico}

- ¿Con qué nombre se conoce al queso de Villalón?

- ¿En qué calle se localiza el Museo del Queso? (Aula)

- ¿En qué mes se celebra el Mercado del Queso y qué actividades desarrolla? (Aula)

- ¿De quién es la escultura dedicada a la Quesera?, en qué año se instaló ? (Aula)

\section{4..3.3. Villalón fue una villa rica merced a las Ferias}

- Localiza una casa blasonada, ¿en qué calle la has encontrado? Fotografíala.

- El rollo de justicia de Villalón es único en España por su ornamentación. De ahí el dicho popular "Campanas las de Toledo, catedral la de León, reloj el de Benavente y rollo el de Villalón". Fotografía un detalle.

- ¿Para qué fueron utilizados los Rollos de la Justicia? (Aula) 
- Las plazas eran fundamentales para la instalación de las ferias y mercados. Escoge dos aspectos de la plaza que te parezcan interesantes y fotografíalos.

- La plaza sigue siendo un lugar de referencia en la vida del pueblo. Haz un repaso a los establecimientos comerciales y de servicios que se localizan en la plaza. Anota sus nombres y a qué se dedican.

\subsubsection{La arquitectura tradicional y contemporánea}

- Identifica tres tipos de edificios según los materiales empleados: ladrillo, piedra, adobe, mixto. Fotografíalos.

- Indica en el plano dos edificios nuevos que respeten las formas y los materiales de la arquitectura tradicional de la comarca y otros dos que se diferencien claramente e incorporen elementos y materiales ajenos a dicha arquitectura. Escribe por qué los clasificas de una u otra forma.

- En Villalón se han levantado, en los años 1990, un conjunto de casas unifamiliares. ¿Dónde se localizan en el plano? Obtén una foto de ellas.

\subsubsection{Un centro comarcal}

- La variedad de equipamientos y servicios

o Busca en internet en el Directorio de Instalaciones Deportivas, Culturales y Sociales de Villalón. (Aula)

o Cuántos Museos tiene Villalón de Campos (Aula)

o Qué centros educativos hay en Villalón de Campos (Aula)

- La importancia comarcal de Villalón de Campos también se manifiesta en el número de establecimientos hosteleros y alojamientos. Anota el nombre de tres de ellos y la calle o plaza en la que se encuentran.

\subsubsection{Sobre el plano (Aula)}

- Localiza el Polideportivo Municipal

- La Plaza del Rollo

- La Iglesia de San Juan

- El Colegio Público Comarcal "Tierra de Campos"

- La carretera Nacional 610 de Palencia a Benavente 


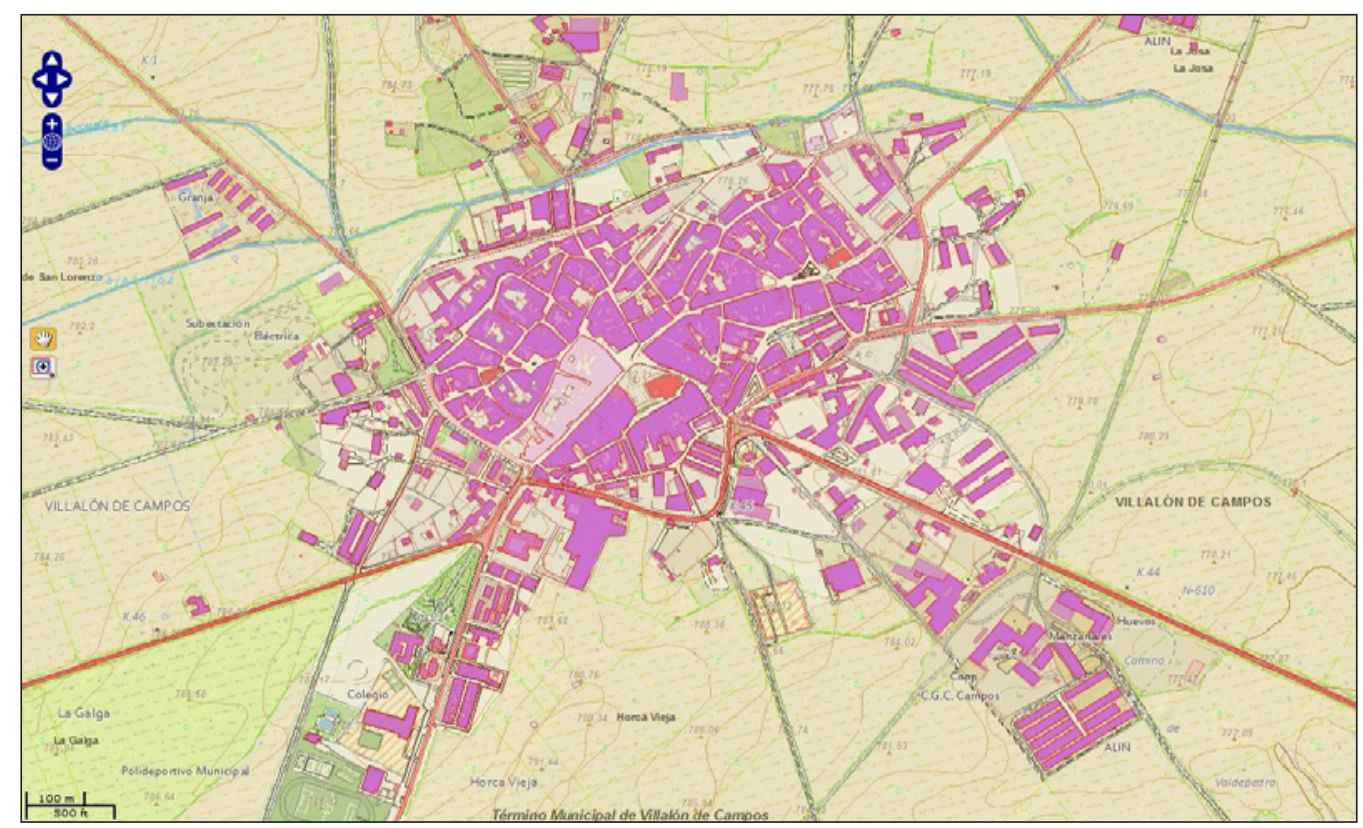

FIGURA 10. Villalón de campos. Fuente: IDECyL

\subsection{Actividades de síntesis}

\subsubsection{Ahora, ya sabemos más (Aula)}

- La mitad del grupo elaborará un resumen de lo que han visto y han leído sobre la localidad de Torremormojón y la otra mitad lo hará sobre Villalón de Campos. Puede hacerse como un ejercicio individual o como uno de escritura colectiva.

- En ambos casos se dejará espacio para enumerar las similitudes y las diferencias que existen entre ambos municipios.

- Compara la actividad de Villalón y la de Torremormojón

\begin{tabular}{|l|c|c|c|c|}
\hline \multirow{2}{*}{} & \multicolumn{2}{|c|}{ Trabajadores } & \multicolumn{2}{c|}{ Empresas } \\
\cline { 2 - 5 } & Villalón & Torremormojón & Villalón & Torremormojón \\
\hline Agricultura & 104 & 4 & 14 & 1 \\
\hline Industria & 19 & 0 & 5 & 0 \\
\hline Construcción & 41 & 3 & 2 & 1 \\
\hline Servicios & 291 & 3 & 50 & 2 \\
\hline Total & 457 & 10 & 71 & 4 \\
\hline
\end{tabular}

TABla 1. Trabajadores y empresas por municipio y sector de la actividad. 2015.

Fuente: Tesorería de la Seguridad Social 
- Con las fotografías, los croquis y dibujos que hemos realizado en la salida y el trabajo de síntesis realizaremos una presentación sobre ambos pueblos siguiendo el modelo de lectura de Liceras que aparece en la Figura 1, estableciendo relaciones, semejanzas y diferencias entre ambos.

- Podemos en internet acceder a la obra pictórica de autores como Juan Manuel Díaz Caneja, Félix Cuadrado Lomas o Aurelio García Lesmes y analizar las distintas formas de representación de la Tierra de Campos.

\section{CONCLUSIONES}

Para generar cultura de paisaje es necesario poner a los escolares en contacto directo con el territorio, ayudarles a entender las formas y los elementos que observamos y las múltiples interrelaciones que se producen en su seno. Esto es particularmente importante cuando hablamos de los paisajes rurales, máxime si consideramos que imparablemente va creciendo el desconocimiento, el desapego y el desinterés por lo que sucede en el medio rural. Al proponer un acercamiento de los escolares al espacio rural tratamos de descubrir el atractivo y el interés que presentan estos paisajes de los que, además, pueden obtenerse aprendizajes valiosos y significativos en distintas áreas de conocimiento, en un entorno que posee condiciones propicias para realizar una salida de campo que favorezca un encuentro fructífero con los elementos, el patrimonio, los habitantes y los valores del paisaje rural.

La propuesta se basa en un acercamiento al territorio mediante un proyecto en el que el contacto directo con el mismo se convierte en el eje alrededor del cual se disponen el conjunto de las herramientas y los recursos utilizables para el conocimiento y la comprensión del espacio considerado. El espacio rural, en este caso, se convierte en objeto y sujeto de los aprendizajes de los escolares a quienes se les implica en la fase de preparación de la salida, en empleo de técnicas y destrezas de análisis y representación y en la búsqueda, organización, síntesis y comunicación de la información, con el objeto no solo de conocer y empatizar con la realidad del territorio, sino de establecer relaciones e interdependencias entre los distintos elementos del paisaje y el territorio donde se sustentan. Las sugerencias contenidas en el proyecto, por su flexibilidad, facilitan su puesta en práctica y van encaminadas a lograr el propósito enunciado.

\section{BIBLIOGRAFÍA}

Baraja Rodríguez, Eugenio. (2011). "Las campiñas cerealistas: Tierra de Campos” en Molinero, F. Ojeda, J. F. y Tort, J. Los paisajes agrarios de España, pp. 218-239. 
Busquets, J. (2010). "La educación en paisaje: una oportunidad para la escuela". Íber, Didáctica de las Ciencias Sociales, Geografía e Historia, 65, pp. 7-16.

Blanco, R. et al (2016). "Bases para la puesta en marcha de un modelo de recuperación ambiental del paisaje de Tierra de Campos (Castilla y León, España)". Cuadernos de la Sociedad Española de Ciencias Forestales, 44, pp. 519-532.

Cabero Diéguez, Valentín et al (ed.) (1992). El medio rural español: cultura, paisaje y naturaleza: homenaje a don Angel Cabo Alonso. 2 VOL. Universidad de Salamanca.

Castiglioni, B. (2010). "La experiencia educativa en el paisaje: el proyecto 3KCL" Íber:

Didáctica de las Ciencias sociales, Geografía e Historia, 65, pp. 44-55.

Cortes Pedrosa, Juan (2014). "Los paisajes del barro" Observatorio Medioambiental, 17, pp. 45-63.

Consejo de Europea. (2000). Convenio Europeo del Paisaje. UE.

Delgado Bujalance, B. y Ojeda Rivera, J.F. (2009). "La comprensión de los paisajes agrarios españoles. Aproximación a través de sus representaciones”. Boletín de la A.G.E.N. ${ }^{\circ} 51$ pp. 93-126.

Delgado Bujalance, B. y Ojeda Rivera, J.F. (2007). "El viaje pedagógico como método de conocimiento de paisajes. Aplicación a Andalucía". En Investigaciones Geográficas n $\mathrm{n}^{\circ}$ 44. pp. 5-31.

Delgado Huertos, E.(2015). "El paisaje en la formación de maestros. Un recurso educativo de alto interés para la educación primaria". Tabanque: Revista pedagógica, 28, pp. 117-137.

Delgado Huertos, E. y Alario Trigueros, $M^{\mathrm{a}}$ T. (1994). "La interacción fuera del aula: itinerarios, salidas y paseos”. Tabanque. Revista pedagógica, 9, pp. 155-178.

Fernández García, F. (2010). "La representación gráfica de los paisajes rurales: Cuestiones de método". Ería: Revista cuatrimestral de geografía, 83, pp. 237-259.

GAMA (2004). Diagnóstico del agua y los residuos agropecuarios en 42 municipios de la provincia de Valladolid. Ficha de Villalón de Campos. Diputación de Valladolid.

García, L. (Coor.), (1988), Análisis del medio físico (Valladolid y Palencia). Junta de Castilla y León. Consejería de Fomento. Valladolid.

Liceras Ruiz, A. (2003). Observar e interpretar el paisaje. Estrategias didácticas. Granada. Grupo Editorial Universitario.

Liceras Ruiz, A. (2013). "Didáctica del paisaje. Lo que es, lo que representa, como se vive”. Íber, Didáctica de las Ciencias Sociales, Geografía e Historia, 74, pp. 85-93.

Malmierca Zurdo, M. (2009). Inventario de palomares de la Tierra de Campos Palentina. Edita Grupo ARADUEY-CAMPOS. Palencia. 
Molinero Hernando, F (coord. general); Tort, J. y Ojeda, J.F.et al. (2013). Atlas de los paisajes agrarios de España. 2. Las unidades de paisaje agrario de la España mediterránea. Ministerio de Agricultura, Alimentación y Medio Ambiente. Madrid.

Molinero Hernando, F; Ojeda, J.F. y Tort, J. (coords). (2011). Los paisajes agrarios de España: caracterización, evolución tipificación, Edita MARM Madrid.

Molinero Hernando, F. (2011). «Paisajes y economías agrarias: del policultivo de subsistencia a la especialización agraria mundial»; en Leco Berrocal, F.; Pérez Díaz, A. y Mateos Rodríguez, B. (coords.): XV Coloquio de Geografía Rural. Geografía y Desarrollo Rural. Territorio, Paisaje y Patrimonio. Ponencias, Ministerio de Medio Ambiente y Medio Rural y Marino-Confederación Hidrográfica del Guadiana, Cáceres, 2011; pp. 5-56.

Orden ECD/686/2014, de 23 de abril, por la que se establece el currículo de la Educación Primaria para el ámbito de gestión del Ministerio de Educación, Cultura y Deporte y se regula su implantación, así como la evaluación y determinados aspectos organizativos de la etapa.

Orden EDU/519/2014, de 17 de junio, por la que se establece el currículo y se regula la implantación, evaluación y desarrollo de la educación primaria en la Comunidad de Castilla y León.

Pavón Gamero, D. et al (eds.) (2014). XVII Coloquio de Geografía Rural. Revalorizando el espacio rural: leer el pasado para ganar el futuro. Girona. Documenta Universitaria.

Pena Vila, R. (1997). "La enseñanza de la Geografía: perspectivas de futuro. Aportaciones para una didáctica el paisaje”. Didáctica Geográfica. Segunda Época, 2. Madrid, pp. 67-74.

Pérez Urraza, K. et al. (2015). "El paisaje un concepto básico en el currículum desarrollado en los libros de texto del País Vasco". Espacio, Tiempo y Educación, Vol. 2, $N^{o} .2$, pp. 225-242.

PGOU - Flórez González, J.A. et al (1991). P.G.O.U. de Villalón de Campos. Memoria. Ayuntamiento de Villalón.

Plaza Gutiérrez, J.I. (2016). "El valor patrimonial de los paisajes rurales. Algunos ejemplos". Paisaje, cultura territorial y vivencia de la geografía: libro homenaje al profesor Alfredo Morales Gil. Vera-Rebollo, J (coor.).et al., pp. 343-360.

Sainz Guerra, J.L. (coor.) (2014). Estudio de la tipología arquitectónica y urbanística en el medio rural de la provincia de Valladolid. ETS Arquitectura y Diputación de Valladolid. 
Sánchez Sanz, M. E. (1979). "Los palomares en la tierra de Campos Palentina". Narria, 14. pp. 11-13.

Sancho Comíns, J. (2016). "El paisaje rural como recurso docente: ejemplos de aplicación en la provincia de Guadalajara”. En Olcina Cantos, J.; Rico Amorós, A. (coords.). Libro Jubilar en Homenaje al Profesor Antonio Gil Olcina. Universidad de Alicante, pp. 417-433.

Tort, Joan. (2004). "El Paisaje como Pedagogía del Territorio" Didáctica Geográfica, 6. pp. 133-153.

Vaca, A. (1992). "La Tierra de Campos y sus bases ecológicas en el siglo XIV". Studia histórica. Historia medieval, Vol. X, pp. 149-185. 